\title{
ANÁLISE dOS ELEMENTOS CLIMÁTICOS EM PRESIDENTE PRUDENTE/SP SOB A ATUAÇÃO DO LA NIÑA (2007-2008) E EL NIÑO (2015-2016)
}

\author{
Laércio Yudi Watanabe Silva, Margarete Cristiane de Costa Trindade Amorim \\ Universidade Estadual Paulista - UNESP. E-mail: laercio.yudi@unesp.br
}

\section{RESUMO}

Este trabalho analisa os elementos climáticos de Presidente Prudente em dois momentos: sob a atuação do La Niña, entre 2007-2008, e El Niño, 2015-2016. O recorte temporal utilizado em ambos os períodos é de 12 meses. Tem-se, como objetivo geral analisar a variabilidade dos elementos do clima na cidade sob o efeito desses dois fenômenos que ocorrem no oceano Pacífico e que tem repercussões no clima em escala planetária. A metodologia utilizada foi a coleta e tratamentos dos dados mensais dos elementos do clima em ambos os períodos, tendo como fonte a estação meteorológica automática do Instituto Nacional de Meteorologia (INMET) - A707 - P.P - SP. Os dados possibilitaram a elaboração das tabelas de cada período, para efeito comparativo. As análises trazidas nesse trabalho permitem a identificação de possíveis variações nos elementos do clima resultantes das oscilações originadas pelos fenômenos do El Niño e La Niña.

Palavras chave: La Niña; EI Niño. Variabilidade Climática. Fenômenos Climáticos. Elementos do Clima.

\section{ANALYSIS OF THE CLIMATE ELEMENTS IN PRESIDENTE PRUDENTE/SP UNDER THE ACTION OF LA NIÑA (2007-2008) AND EL NIÑO (2015-2016)}

\begin{abstract}
This paper analyzes the climate elements of Presidente Prudente in two moments: under the actions of $L a$ Niña, between 2007 and 2008, and El Niño, 2015 and 2016. The time frame used in both periods is of 12 months. The general objective is to analyze the variability of the climate elements in the city under the action of both of these phenomena that occur in the Pacific Ocean and that have repercussions in the climate on a planetary scale. The methodology used was the collection and processing of the monthly data of the climate elements in both periods, having as source the automatic meteorological station of the National Institute of Meteorology (Brazilian acronym: INMET) - A707 - P.P - SP. The data enabled the elaboration of tables of every period, for comparative purposes. The analyses shown in this paper enable the identification of possible variations in the climate elements resulting from the oscillations originated by the phenomena EI Niño and La Ninã.
\end{abstract}

Keywords: La Niña. El Niño. Climatic Variability. Climatic Phenomena. Climate Elements.

\section{INTRODUÇÃO}

A principal fonte de variabilidade climática interanual global é consequência do fenômeno El Niño-Oscilação Sul (ENOS), sendo esta uma oscilação acoplada do oceanoatmosfera, que produz alterações na temperatura da superfície do mar (TSM), na pressão, no vento, e na convecção tropical, principalmente no oceano Pacífico, mas com reflexos em muitos lugares do planeta, incluindo o Brasil (GRIMM, 2009). As fases opostas dessa oscilação são denominadas episódios El Niño (EN) e La Niña (LN). 
Segundo o Instituto Nacional de Pesquisas Espaciais ${ }^{1}$, o El Niño e a La Niña são partes de um mesmo fenômeno atmosféricooceânico que ocorre no oceano Pacífico Equatorial (e na atmosfera adjacente), denominado de EI Niño Oscilação Sul (ENOS). O ENOS refere-se às situações nas quais o oceano Pacífico Equatorial está mais quente (EI Niño) ou mais frio ( $L a N i n ̃ a)$ do que a média normal histórica. A mudança na temperatura do oceano Pacífico Equatorial acarreta efeitos globais na temperatura e na precipitação.

A região em que Presidente Prudente está inserida sofre influência tanto de massas de ar tropicais quanto de massas subtropicais, como a Polar Atlântica, tendo um clima bastante variável e contrastante ao longo do ano, evidenciado por meio da falta de regularidade anual no que concerne aos elementos do clima (BRAIDO; TOMASELLI, 2010). Tal cidade possui um período quente e chuvoso entre outubro e março, e outro mais ameno e seco, entre abril e setembro (AMORIM et al., 2009). De acordo com os valores médios de temperatura do ar e precipitação, a cidade encontra-se sob o regime de clima tropical com estação seca de inverno (Aw), segundo a classificação de Köppen (Dubreuil, 2018).

Mesmo com as classificações climáticas para cada localidade, verifica-se que os elementos do clima podem sofrer grandes variações em curtos períodos de tempo, por meio da ação dos fatores do clima ${ }^{2}$. A variabilidade climática é entendida como sendo a maneira pela qual os elementos do clima variam no interior de determinado período de registro, expressos através do desvio padrão ou coeficiente de variação (OMM, 1966).

É importante ressaltar que fenômenos que interferem nas interações entre a atmosfera e a superfície, regulares ou não, fomentam essa variabilidade climática, como o El Niño e La Niña. $O$ primeiro caracteriza-se como sendo $O$ "fenômeno responsável por um forte aquecimento das águas superficiais do Oceano Pacífico, principalmente nas porções leste e central" (COSTA; SARTORI; FANTINI, 2007, p. 268). Por outro lado, o La Niña provoca o resfriamento das águas da costa oeste da América do Sul. Ambos os fenômenos interferem

\footnotetext{
1 INPE - Instituto Nacional de Pesquisas Espaciais http://enos.cptec.inpe.br (acesso em 11 de agosto de 2020).

${ }^{2}$ Estes, interferem nos elementos do clima, concorrendo para uma maior variabilidade climática.
}

no padrão da circulação geral da atmosfera e, consequentemente, ocasionam relativas variações climáticas em regiões da América do Sul.

O presente trabalho tem como objetivo analisar a variabilidade dos elementos climáticos em Presidente Prudente, sob o efeito dos fenômenos El Niño $(2015 / 16)$ e La Niña (2007/08).

\section{METODOLOGIA}

Para atingir os objetivos da pesquisa, foram tratados os dados dos elementos clima registrados na estação meteorológica automática - A707 - P.P - SP, além de dados disponibilizados pelo INMET $^{3}$ (Instituto Nacional de Meteorologia). Na Figura 1 e Tabela 1 foram organizados os dados históricos da cidade, para efeito comparativo com os fenômenos climáticos em análise neste trabalho. Na Figura 1 representamos a precipitação acumulada histórica da cidade entre 1969 e 2015 . Para representação dos dados históricos da temperatura, recorremos a elaboração da Tabela 2 , referente ao recorte temporal entre os anos de 1971 e 2007.

Para as Tabelas 2 e 3 também tratados e organizados os dados da referida estação meteorológica, com menção aos elementos do clima, como: temperatura, média mensal, máxima mensal e mínima mensal; umidade relativa média mensal; precipitação acumulada no mês; pressão atmosférica média mensal; velocidade do vento média mensal; direção predominante dos ventos no mês. Os meses escolhidos foram de julho a junho, meses de maior intensidade dos fenômenos nos respectivos anos de ocorrência. Todos esses dados referentes aos dois fenômenos climáticos, La Niña e El Niño, foram apresentados de forma comparativa em relação aos dados históricos da cidade (Figura 1 e Tabela 1).

Por fim, foram sintetizadas as análises referentes a atuação de ambos os fenômenos, $E I$ Niño e La Niña, por meio da organização do Quadro 1, a partir dos dados já levantados. A síntese possibilitou a elaboração de conclusões mais assertivas sobre a atuação dos fenômenos climáticos na cidade de Presidente Prudente no período de análise.

\footnotetext{
${ }^{3}$ Disponível em: https://mapas.inmet.gov.br/. A ferramenta permite o acesso aos dados de cidades que possuem estações automáticas ou convencionais.
} 


\section{RESULTADOS E DISCUSSÃO}

Nas Figura 1, para efeito comparativo, observa-se os dados históricos da precipitação mensal acumulada, entre 1969 e 2015. Mais abaixo, na Tabela 1, tem-se os dados históricos referentes a temperatura média, temperatura máxima e mínima média do ar entre 1971-2007.

Figura 1. Precipitação mensal $(\mathrm{mm})$, Temperatura média, máxima e mínima mensal $\left({ }^{\circ} \mathrm{C}\right)$ de Presidente Prudente-SP entre 1969 a 2015.

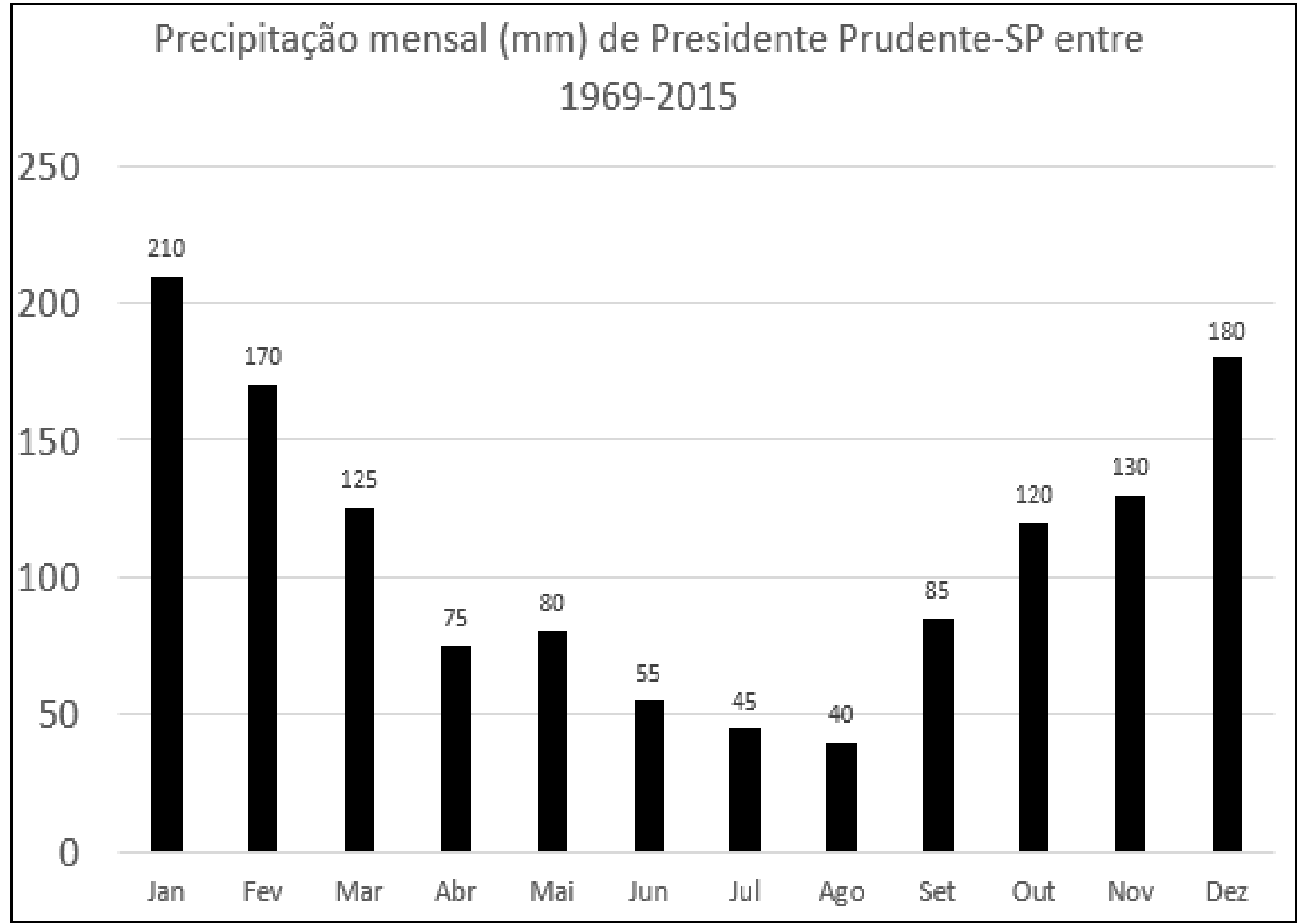

Fonte: Inmet - Instituto Nacional de Meteorologia localizada na Faculdade de Ciências e Tecnologia - UNESP.

Tabela 1. Temperatura média, temperatura máxima média e temperatura mínima média $\left({ }^{\circ} \mathrm{C}\right)$ de Presidente Prudente-SP entre 1971-2007

\begin{tabular}{|lrrrrr|}
\hline Temperatura $\left({ }^{\circ} \mathrm{C}\right)$ & $\mathbf{7 1 - 8 0}$ & $\mathbf{8 1 - 9 0}$ & $\mathbf{9 1 - 2 0 0 0}$ & $\mathbf{2 0 0 1 - 2 0 0 7}$ & $\mathbf{7 1 - 2 0 0 7}$ \\
\hline Média & $22,8^{\circ} \mathrm{C}$ & $23,2^{\circ} \mathrm{C}$ & $23,6^{\circ} \mathrm{C}$ & $24,1^{\circ} \mathrm{C}$ & $23,4^{\circ} \mathrm{C}$ \\
Mínima média & $17,7^{\circ} \mathrm{C}$ & $18,4^{\circ} \mathrm{C}$ & $18,8^{\circ} \mathrm{C}$ & $19,2{ }^{\circ} \mathrm{C}$ & $18,5^{\circ} \mathrm{C}$ \\
Máxima média & $28,7^{\circ} \mathrm{C}$ & $28,9^{\circ} \mathrm{C}$ & $29,2^{\circ} \mathrm{C}$ & $29,8^{\circ} \mathrm{C}$ & $29,1^{\circ} \mathrm{C}$ \\
\hline
\end{tabular}

Fonte: Inmet - Instituto Nacional de Meteorologia localizada na Faculdade de Ciências e Tecnologia - UNESP.

Visualiza-se na Figura 1 a irregularidade da precipitação ao longo do ano, sendo concentrada nos meses mais quentes, principalmente de outubro a março (valores superiores a $120,0 \mathrm{~mm}$ ), enquanto que nos meses mais frios, são registrados os menores volumes, com médias próximas de $50,0 \mathrm{~mm}$ entre junho e agosto. Janeiro é o único mês com média superior a $200 \mathrm{~mm}$, seguidos por dezembro (180 $\mathrm{mm}$ ) e fevereiro $(170 \mathrm{~mm})$.

Em relação a temperatura histórica do ar na cidade, Tabela 1, notamos o gradativo aumento nas temperaturas média, máxima e mínima do ar nos recortes temporais analisados. A diferença entre a temperatura média entre 1971-1980 e 2001-2007 é $1,3{ }^{\circ} \mathrm{C}$; o primeiro período teve uma temperatura média de $22,8^{\circ} \mathrm{C}$, enquanto que $\mathrm{O}$ segundo de $24,1{ }^{\circ} \mathrm{C}$. A temperatura mínima média teve variação de 1,5 ${ }^{\circ} \mathrm{C}$, considerando a comparação entre os mesmos períodos, e a temperatura média máxima variou $1,1^{\circ} \mathrm{C}$ 
Observa-se na Tabela 1 , as variáveis período de julho de 2007 a junho de 2008. climáticas referentes ao fenômeno La Niña no

Tabela 2. Presidente Prudente. Dados climáticos sob a incidência do fenômeno La Niña, de julho de 2007 a junho de 2008.

\begin{tabular}{|c|c|c|c|c|c|c|c|c|}
\hline Data & $\mathrm{T}\left({ }^{\circ} \mathrm{C}\right)$ & $\begin{array}{l}\text { T. } \max \\
\left({ }^{\circ} \mathrm{C}\right)\end{array}$ & $\begin{array}{l}\text { T. } \min \\
\left({ }^{\circ} \mathrm{C}\right)\end{array}$ & UR (\%) & $\begin{array}{l}\text { Precip. } \\
\text { (mm) }\end{array}$ & $\begin{array}{l}\text { P. Atm. } \\
\text { (hPa) }\end{array}$ & $\mathrm{VV}(\mathrm{m} / \mathrm{s})$ & D.V \\
\hline jul/07 & 19,1 & 25,1 & 14,5 & 57,1 & 0,2 & 965,7 & 2,1 & SE \\
\hline ago/07 & 21,8 & 28,3 & 16,2 & 50,7 & 1,6 & 965,8 & 2,4 & SE \\
\hline set/07 & 26,0 & 32,1 & 20,2 & 40,7 & 13,0 & 964,5 & 2,7 & $\mathrm{E}$ \\
\hline out/07 & 26,2 & 32,6 & 20,6 & 52,8 & 58,8 & 961,6 & 2,3 & SE \\
\hline nov/07 & 24,2 & 29,7 & 19,3 & 64,3 & 185,0 & 959,8 & 2,3 & SE \\
\hline dez/07 & 25,7 & 31 & 21,3 & 62,0 & 80,8 & 959,9 & 1,8 & SE \\
\hline jan/08 & 24,3 & 29,2 & 17,8 & 73,5 & 196,2 & 960,1 & 2,0 & SE \\
\hline fev/08 & 24,9 & 30,1 & 19,7 & 70,8 & 199,6 & 961,1 & 1,6 & SE \\
\hline mar/08 & 24,3 & 29,3 & 20,2 & 68,2 & 178,2 & 961,5 & 1,7 & SE \\
\hline $\mathrm{abr} / 08$ & 23,4 & 28,3 & 19,3 & 68,6 & 99,2 & 961,4 & 1,5 & SE \\
\hline mai/08 & 19,9 & 24,9 & 15,8 & 64,3 & 63,6 & 965,3 & 1,5 & SE \\
\hline jun/08 & 19,5 & 25,1 & 15,3 & 65,8 & 14,4 & 966,6 & 1,6 & SE \\
\hline \multicolumn{9}{|c|}{ LEGENDA } \\
\hline$T$ & \multicolumn{3}{|c|}{ Temperatura média do mês } & Precip. & \multicolumn{4}{|c|}{$\begin{array}{l}\text { Precipitação mensal acumulada em } \\
\text { milímetros (0h a 23h) }\end{array}$} \\
\hline T. $\max$ & \multicolumn{3}{|c|}{ Temperatura média das máximas } & S P. Atm & \multicolumn{4}{|c|}{$\begin{array}{c}\text { Pressão atmosférica média mensal em } \\
\text { hectoPascal }\end{array}$} \\
\hline T. $\min$ & \multicolumn{3}{|c|}{ Temperatura média das mínimas } & VV & \multicolumn{4}{|c|}{$\begin{array}{l}\text { Velocidade do vento média mensal em } \\
\text { metros por segundo }\end{array}$} \\
\hline UR & \multicolumn{3}{|c|}{ Umidade Relativa média do mês } & D.V & \multicolumn{4}{|c|}{ Direção do vento média mensal (quadrante) } \\
\hline
\end{tabular}

Fonte: Estação meteorológica automática A707 - P. P. - SP (2007-2008).

Os dados apresentados na Figura 1 e na Tabela 2, permitem afirmar que o La Niña, nos anos de 2007 e 2008, provocou redução na precipitação acumulada na cidade de Presidente Prudente. Os resultados observados na média histórica da cidade (Figura 1), revelam que nenhum dos meses apresentam médias de precipitações acumuladas inferiores a $30,0 \mathrm{~mm}$; neste episódio de ocorrência do La Niña, os meses de julho, agosto e setembro de 2007 e junho de 2008, não chegaram sequer a acumular $20,0 \mathrm{~mm}$ de precipitação, valores muito abaixo da média histórica. A temperatura média histórica entre 1971 e 2007 foi de $23,4^{\circ} \mathrm{C}$; a máxima média de $29,1{ }^{\circ} \mathrm{C}$; e a mínima média de $18,5{ }^{\circ} \mathrm{C}$. Em comparação com os dados de temperatura sob o efeito do La Niña, o mês de outubro de 2007 registrou a maior temperatura média do período com $26,2^{\circ} \mathrm{C}, 2,8^{\circ} \mathrm{C}$ superior à média história de $23,4^{\circ} \mathrm{C}$.

Observou-se uma redução na precipitação acumulada nos anos de 2007/08 (Tabela 2), quando comparado aos valores históricos (Figura 1). Não são observados valores inferiores a $30,0 \mathrm{~mm}$ nas normais climatológicas. Nos meses de agosto e setembro de 2007 e junho de 2008, observou-se precipitações mensais abaixo de $20,0 \mathrm{~mm}$. 
Tabela 3. Presidente Prudente. Dados climáticos sob a incidência do fenômeno El Niño, de julho de 2015 a junho de 2016.

\begin{tabular}{|c|c|c|c|c|c|c|c|c|}
\hline Data & $\mathrm{T}\left({ }^{\circ} \mathrm{C}\right)$ & T. $\max \left({ }^{\circ} \mathrm{C}\right)$ & $\begin{array}{l}\text { T. } \min \\
\left({ }^{\circ} \mathrm{C}\right)\end{array}$ & UR (\%) & $\begin{array}{l}\text { Precip. } \\
\text { (mm) }\end{array}$ & $\begin{array}{l}\text { P. Atm. } \\
\text { (hPa) }\end{array}$ & $\mathrm{W}(\mathrm{m} / \mathrm{s})$ & D.V \\
\hline jul/15 & 20,2 & 25,3 & 16,3 & 71 & 153,4 & 967,2 & 1,2 & $\mathrm{E}$ \\
\hline ago/15 & 23,4 & 30,1 & 17,9 & 48 & 15,6 & 966,4 & 1,2 & $E$ \\
\hline set/15 & 24,5 & 30,7 & 19,5 & 59 & 144,4 & 963,1 & 1,1 & $E$ \\
\hline out/15 & 25,4 & 31,6 & 20,4 & 68 & 242,0 & 963,1 & 1,4 & $E$ \\
\hline nov/15 & 25,2 & 30,7 & 21,3 & 75 & 266,8 & 961,0 & 1,0 & $E$ \\
\hline dez/15 & 25,9 & 30,8 & 21,9 & 75 & 203,2 & 962,6 & 1,0 & $E$ \\
\hline jan/16 & 25,8 & 31,5 & 21,8 & 74 & 189,3 & 963,8 & 1,8 & $E$ \\
\hline $\mathrm{fev} / 16$ & 26,2 & 31,8 & 22,4 & 76 & 273,6 & 963,0 & 0,8 & $\mathrm{NE}$ \\
\hline $\mathrm{mar} / 16$ & 25,4 & 31,2 & 20,8 & 68 & 92,2 & 964,2 & 0,9 & $E$ \\
\hline $\mathrm{abr} / 16$ & 26,4 & 32,2 & 21,5 & 53 & 91,0 & 964,1 & 0,9 & $E$ \\
\hline $\mathrm{mai} / 16$ & 19,7 & 25,0 & 15,9 & 75 & 122,9 & 970,2 & 1,0 & SE \\
\hline jun/16 & 18,0 & 24,3 & 12,2 & 70 & 62,6 & 971,8 & 0,7 & SE \\
\hline \multicolumn{9}{|c|}{ LEGENDA } \\
\hline $\mathbf{T}$ & \multicolumn{3}{|c|}{ Temperatura média do mês } & Precip. & \multicolumn{4}{|c|}{$\begin{array}{l}\text { Precipitação mensal acumulada em } \\
\text { milímetros (0h a 23h) }\end{array}$} \\
\hline T. max & \multicolumn{3}{|c|}{ Temperatura média das máximas } & P. Atm & \multicolumn{4}{|c|}{$\begin{array}{c}\text { Pressão atmosférica média mensal em } \\
\text { hectoPascal }\end{array}$} \\
\hline T. $\min$ & \multicolumn{3}{|c|}{ Temperatura média das mínimas } & VV & \multicolumn{4}{|c|}{$\begin{array}{l}\text { Velocidade do vento média mensal em } \\
\text { metros por segundo }\end{array}$} \\
\hline UR & \multicolumn{3}{|c|}{ Umidade Relativa média do mês } & D.V & \multicolumn{4}{|c|}{ Direção do vento média mensal (quadrante) } \\
\hline
\end{tabular}

Fonte: Estação meteorológica automática A707 - P. P. - SP (2015-2016).

Diferentemente do ocorrido com o La Niña entre 2007 e 2008, o fenômeno climático do El Niño, atuante em 2015 e 2016, provocou aumento nas precipitações acumuladas em Presidente Prudente. 0 mês de outubro, que possui média histórica de 120,0 mm entre 1969 e 2015 (Figura 1), registrou, em 2015, 242,0 mm de precipitação acumulada, valor este, 201,6\% superior à média histórica para o mês. As precipitações também foram melhor distribuídas nos meses do ano. Apenas no mês de agosto de 2015 se registrou precipitação acumulada inferior a 50,0 $\mathrm{mm}$. Os meses de outubro e novembro de 2015 e fevereiro de 2016 tiveram registros de mais de $240,0 \mathrm{~mm}$ de precipitação acumulada; por outro lado, o mês de maior registro de precipitação média histórica foi de $210,0 \mathrm{~mm}$, em janeiro. As temperaturas médias observadas no período de 2015 e 2016 variaram de $18{ }^{\circ} \mathrm{C}$ a 26,2 ${ }^{\circ} \mathrm{C}$ de média, enquanto que a média histórica registrada de 1971 a 2007 é de $23,4{ }^{\circ} \mathrm{C}$; apenas dos meses de julho de 2015 e maio e junho de 2016 registraram temperaturas médias abaixo da média histórica de $23,4{ }^{\circ} \mathrm{C}$, todos os demais registraram médias acima, com destaque para os meses de fevereiro e maio de 2016, que registraram temperaturas médias acima de 26,0 ${ }^{\circ} \mathrm{C}$.

Por fim, no Quadro 3, sintetizam-se, para efeitos comparativos, de maneira a facilitar as análises e interpretações, os dados referentes aos fenômenos do El Niña e El Niño 
Quadro 1. Presidente Prudente: Quadro síntese comparativo dos elementos do clima sob atuação dos fenômenos do El Niño e La Niña

\begin{tabular}{|cccc|}
\hline & $\begin{array}{c}\text { Média } \\
\text { Histórica }\end{array}$ & $\begin{array}{c}\text { La Niña } \\
\text { (jul/2007 a } \\
\text { jun/2008) }\end{array}$ & $\begin{array}{c}\text { El Niño } \\
\text { (jul/2015 a } \\
\text { jun/2016) }\end{array}$ \\
\hline $\begin{array}{c}\text { Temperatura média anual } \\
\text { Temperatura máxima média } \\
\text { anual }\end{array}$ & 23,4 & 23,3 & 23,8 \\
$\begin{array}{c}\text { Temperatura mínima média } \\
\text { anual }\end{array}$ & 29,1 & 28,8 & 29,6 \\
$\begin{array}{c}\text { Precipitação acumulada anual } \\
\text { Pressão média anual }\end{array}$ & 18,5 & 18,3 & 19,3 \\
\hline
\end{tabular}

Fonte: Estação meteorológica automática A707 - P. P. - SP.

A precipitação média histórica anual acumulada de Presidente Prudente no período entre 1969 e 2015 é de 1315,0 mm. A precipitação acumulada durante o período de atuação do La Niña em nosso recorte temporal é de 1090,6 $\mathrm{mm}$, o que corresponde a $82,9 \%$ da precipitação média histórica anual acumulada; já o total acumulado no El Niño, de $1857,0 \mathrm{~mm}$, corresponde a $141,2 \%$ da precipitação média histórica anual acumulada. Demonstramos, assim, que o El Niño provocou precipitações acumuladas muito superiores à média histórica, sobretudo no ano de 2015 , diferentemente do $L a$ Niña.

No período entre outubro a março, temos um total acumulado $898,6 \mathrm{~mm}$ durante o período de atuação do La Niña considerado neste trabalho, o que corresponde a $96,1 \%$ da precipitação média histórica acumulada de Presidente Prudente nesses mesmos meses, que chegam a $935,0 \mathrm{~mm}$. Considerando o período de atuação do El Niño, o total acumulado de outubro a março é de $1267,1 \mathrm{~mm}$, o que corresponde a $135,5 \%$ dos $935,0 \mathrm{~mm}$ da precipitação média histórica acumulada. Sendo assim, em ambos os recortes temporais, primeiro considerando um período de 12 meses e posteriormente de outubro a março, a precipitação acumulada do $E I$ Niño sempre esteve em pelo menos $130 \%$ em relação à média histórica da cidade, enquanto que as precipitações registradas durante 0 período de atuação do La Niña sempre tiveram resultados absolutos menores que a média histórica da cidade.

Sobre a quantidade de precipitação acumulada no ano de 2015, Amorim (2017) considera $o$ ano como atípico em relação a distribuição da precipitação. Ainda segundo a autora, o referido ano registrou um total de
$1854,0 \mathrm{~mm}$ de precipitação acumulada, enquanto que a média entre os anos de 1943-2014 foi de $1308,0 \mathrm{~mm}$. Sendo assim, o período de atuação do El Niño, neste recorte temporal, apresentou um volume total de precipitações bem acima do período elencado para análise da atuação do $L a$ Niña e em relação à média história da cidade, muito em função da atipicidade do ano de 2015.

Amorim (2001), ao analisar, também, os efeitos da atuação do El Niño e La Niña em Presidente Prudente, no período de 1969 a 1998, afirma que "[...] nem em todos os anos em que estiveram presentes foram significativamente suficientes para causar variações, sendo estas restritas a outras regiões do país (AMORIM, 2001, p. 131). Com isso, a autora denota que ambos os fenômenos climáticos atuam com maior intensidade em outras regiões do país, com variações dos elementos do clima pouco significativas para a região de Presidente Prudente.

Essa afirmação comprova também a atipicidade do ano de 2015, pois em suas análises, também referentes a atuação do El Niño e La Niña de 1969 à 1998, a autora não identificou grandes diferenças entre os elementos do clima, diferentemente do resultado encontrado na presente pesquisa, em relação as precipitações acumuladas no período analisado. Não se pode generalizar ao afirmar que o fenômeno do El Niño sempre irá causar o aumento das precipitações na região de Presidente Prudente. Considerando ambos os recortes temporais, de 2007/2008 e 2015/2016, as diferenças da precipitação acumulada entre os dois períodos são de aproximadamente 800,0 $\mathrm{mm}$, sendo esta, bastante significativa em um curto intervalo de tempo entre esses anos. Todos os outros elementos climáticos tiveram variações 
muito pequenas, o que demonstra que ambos os fenômenos não atingem significativamente a região e o clima de Presidente Prudente, exceto em relação ao regime de chuvas, neste caso.

As precipitações foram mais regulares sob o efeito do fenômeno do El Niño, com chuvas distribuídas em praticamente todos os meses do ano, inclusive nos meses frios, nos quais a cidade pode enfrentar um longo período de estiagem. No recorte temporal de atuação do La Niña, o período entre os meses de outubro/2007 e maio/2008 foram os únicos meses que apresentaram precipitações significativas, com acumulado de pelo menos $50,0 \mathrm{~mm}$ nesses meses, demonstrando maior irregularidade das precipitações.

A temperatura média máxima histórica entre 1971 e 2007 (Tabela 1 ) foi de $29,1{ }^{\circ} \mathrm{C}, 0,5^{\circ} \mathrm{C}$ a menos em relação à média das máximas sob a atuação do El Niño, revelando pequeno aumento nas temperaturas máximas durante a atuação desse fenômeno climático; a temperatura máxima sob a atuação do La Niña, foi de $28,8^{\circ} \mathrm{C}$, uma pequena variação de $0,3{ }^{\circ} \mathrm{C}$ em relação à média história. Ao olharmos para as temperaturas mínimas médias, o El Niño possui o registro de $19,3{ }^{\circ} \mathrm{C}, 1,0{ }^{\circ} \mathrm{C}$ inferior a temperatura mínima média sob a atuação do La Niña, de 18,3 ${ }^{\circ} \mathrm{C}$, e $0,8{ }^{\circ} \mathrm{C}$ inferior ao compararmos com o registro histórico de $18,5^{\circ} \mathrm{C}$. A amplitude entre as temperaturas máximas e mínimas médias é de $10,3{ }^{\circ} \mathrm{C}$ sob efeito do El Niño e de também de $10,5^{\circ} \mathrm{C}$ em relação ao La Niña, amplitudes muito próximas da variação de $10,6{ }^{\circ} \mathrm{C}$ da média histórica.

\section{CONCLUSÃO}

O fenômeno climático do El Niño é aquele que mais impacta o clima da região de Presidente Prudente em relação a precipitação, aumentando a distribuição e quantidade acumulada, inclusive nos meses mais secos. Durante a atuação do $E I$ Niño, os meses mais chuvosos (outubro e novembro de 2015 e fevereiro de 2016) ultrapassam 240,0 $\mathrm{mm}$ acumulados de precipitação, no registro histórico da cidade e nos dados obtidos na análise da precipitação acumulada sob atuação do La Niña, nenhum dos meses ultrapassou a marca de 210,0 mm acumulados.

Sendo assim, o fenômeno climático do El Niño, no recorte temporal utilizado neste trabalho, foi aquele mais se distanciou, em relação a precipitação, da normal climática para a região de Presidente Prudente. A precipitação se comportou de maneira anômala, ao compararmos com o registro histórico da cidade.

Sobre o La Niña, apenas em relação a quantidade acumulada de precipitação tivemos uma variação significativa, com quatro meses registrando menos de $15,0 \mathrm{~mm}$ acumulados; por outro lado, o menor valor registrado na média histórica é superior aos $30,0 \mathrm{~mm}$. O La Niña resultou numa redução no volume total de precipitação. Ambos os fenômenos climáticos, El Niño e La Niña, não impactaram significativamente a variação da temperatura da região, que continuou se comportando com valores muito próximos da média história para a cidade.

Salientamos a atipicidade do ano de 2015, sob a atuação do EI Niño. Sendo assim, não podemos generalizar ao afirmar que o clima da região de Presidente Prudente sempre sofrerá grandes impactos sob a atuação do El Niño. Nossas analises detectaram variações significativas em relação aos dados históricos, no entanto não deve ser encarada como um padrão, quando este fenômeno climático estiver atuante.

\section{AGRADECIMENTOS}

Agradecemos ao INPE e ao INMET pela disponibilidade de dados e informações em seus respectivos sites oficiais.

0 autor declara não haver qualquer potencial conflito de interesse que possa interferir na imparcialidade deste trabalho científico.

\section{REFERÊNCIAS}

AMORIM, M. C. C. T. Teoria e método para o estudo das ilhas de calor em cidades tropicais de pequeno e médio porte. 178 f. 2017. Tese (Livre Docência em "Climatologia Geográfica) Universidade Estadual Paulista, UNESP, Presidente Prudente, 2017.

AMORIM, M. C. C. T. Análise temporal dos elementos climáticos em Presidente Prudente/SP. Caderno Prudentino de Geografia, Presidente Prudente, v. 1, n. 23, p. 115-131, 2001.

AMORIM, M. C. C. T. ; DUBREUIL, V. ; QUENOL, H. ; SANT'ANNA, J. L. Características das ilhas de calor em cidades de porte médio: exemplos de Presidente Prudente (Brasil) e Rennes (Franca). 
Confins, Online. 7, 2009, p. 1-16. DOI https://doi.org/10.4000/confins.6070.

BRAIDO, L. M. H.; TOMMASELLI, J. T. G. Caracterização climática e dos anos extremos (chuvoso e seco): seus efeitos na produção de cana-de-açúcar, milho e soja para a região do Pontal do Paranapanema-SP. Formação (Online), v. 1, n. 17, 2010.

COSTA, E. R.; SARTORI, M. G. B.; FANTINI, V. Estudo da relação entre eventos El Niño-La Niña e ocorrência de ondas de frio na região de Santa Maria-RS. Boletim Gaúcho de Geografia, v. 33, n. 1, 2007.

DUBREUIL, V. Reutilização da classificação de Köppen para o estudo dos climas brasileiros: os tipos de climas anuais. In: XIII Simpósio Brasileiro de Climatologia Geográfica. 2018.

GRIMM, A. M. Variabilidade Interanual do Clima no Brasil. In: CAVALCANTI, I. F. A. ; FERREIRA, N. J.; M. G. ; SILVA, J. ; SILVA DIAS, M. A. F. (org.). Tempo e Clima no Brasil. São Paulo: Oficina de Textos, 2009, p. 353-374.

OMM. Technic note, 79. Geneve, 1966. 